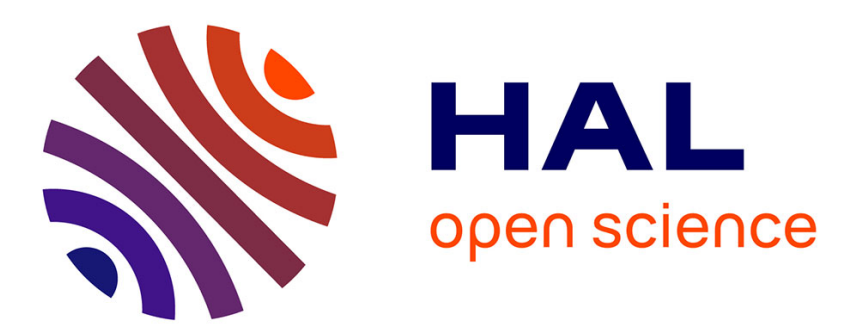

\title{
Simulation of cosmic Be isotopes detected by the RICH in AMS on the ISS
}

Alexandra Bouchet, T. Thuillier, L. Derome, A. Menchaca-Rocha, M. Buenerd

\section{To cite this version:}

Alexandra Bouchet, T. Thuillier, L. Derome, A. Menchaca-Rocha, M. Buenerd. Simulation of cosmic Be isotopes detected by the RICH in AMS on the ISS. Nuclei in the Cosmos 2000, 2000, Aarhus, Denmark. pp.417-420. in2p3-00010941

\section{HAL Id: in2p3-00010941 https://hal.in2p3.fr/in2p3-00010941}

Submitted on 13 Apr 2001

HAL is a multi-disciplinary open access archive for the deposit and dissemination of scientific research documents, whether they are published or not. The documents may come from teaching and research institutions in France or abroad, or from public or private research centers.
L'archive ouverte pluridisciplinaire HAL, est destinée au dépôt et à la diffusion de documents scientifiques de niveau recherche, publiés ou non, émanant des établissements d'enseignement et de recherche français ou étrangers, des laboratoires publics ou privés. 
Simulation of cosmic $B e$ isotopes detected by the RICH in AMS on the ISS

\author{
A. Bouchet, T. Thuillier, L. Derome, A. Menchaca-Rocha*, and M. Buénerd ${ }^{\mathrm{a}}$ \\ ${ }^{a}$ Institut des Sciences Nucléaires \\ 53 av. des Martyrs, 38026 Grenoble cedex, France
}

A sample of cosmic ${ }^{10} \mathrm{Be}$ isotopes has been simulated in the expected experimental conditions for the forthcoming phase of the AMS experiment, and identified by means of the RICH counter. The results are discussed. The high flux proton component observed by AMS below the geomagnetic cutoff can be well accounted for by assuming these particles to be secondaries originating from the interaction of cosmic ray protons with the atmosphere. The simulation results are presented.

\title{
1. Introduction
}

The measurement of the ${ }^{10} \mathrm{Be}$ abundance is one of the main experimental goals in cosmic ray astrophysics of the AMS experiment. It is also highly representative of its discovery potential. Because of its long lifetime, the ${ }^{10} \mathrm{Be}$ isotope is used as a galactic chronometer for the measurement of the time of confinement of Cosmic Rays (CRs) in the galaxy (see refs [1] for example). The measurement of the momentum dependence of the ${ }^{10} \mathrm{Be} /{ }^{9} \mathrm{Be}$ ratio will provide a determination of important transport parameters and galactic variables: mean interstellar matter (ISM) density in the Leaky Box Model (LBM) [2], or size of the confinement halo in the diffusion model [3].

A realistic sample of simulated data for these ions with relevant counting statistics would provide a useful perspective on the physics achievable by the collaboration on this respect. It would also allow to evaluate both the usefulness of the performances considered for the RICH counter of the spectrometer in the current stage of the spectrometer design [4], and the relevancy of the instrumental options proposed for the final configuration of the $\mathrm{RICH}$, in particular the choice of Cerenkov radiators. This contribution reports on such a simulation of the ${ }^{10} \mathrm{Be} /{ }^{9} \mathrm{Be}$ momentum distribution. The work is based on the simulation program developed for the RICH counter, and already used to work out the counter definition [5].

\section{Simulation conditions}

\section{1. $C R$ Event generator}

The simulation used the natural ${ }^{7,9} \mathrm{Be}$ abundances [6], whereas the (theoretical) ${ }^{10} \mathrm{Be} /{ }^{9} \mathrm{Be}$ ratio and its momentum dependence, was taken from the LBM calculations reported in

*On leave from Instituto de Fisica, UNAM, Mexico. 
ref [7]. The momentum dependence of the ${ }^{10} \mathrm{Be} /{ }^{9} \mathrm{Be}$ ratio is shown on figure 2 (solid line).

\subsection{AMS and RICH counter}

A combination of two radiators considered for the final $\mathrm{RICH}$ counter configuration was used in the simulation. A radiator with large refraction index (sodium fluoride, $\mathrm{NaF}$ ) allows to cover the lower momentum region of the sensitivity range of the counter $(\approx 1$ $5 \mathrm{GeV} / \mathrm{c}$ per nucleon), whereas a low index radiator (Silica aerogel, $\mathrm{n}=1.025$ ) covers the high momentum range ( $\approx 4-12 \mathrm{GeV} / \mathrm{c}$ per nucleon). The $\mathrm{RICH}$ counter is a proximity focused type of counter, as studied in ref [5]. Its dimensions were: Radiator diameter $140 \mathrm{~cm}$, drift gap $40 \mathrm{~cm}$, diameter of detector area $140 \mathrm{~cm}$, with central dead area corresponding to the calorimeter location $70 \times 70 \mathrm{~cm}$ inactive [4]. Light attenuation in light guides was taken into account in the simulation, as well as Rayleigh scattering for the aerogel radiator.

The two samples corresponding to $\mathrm{NaF}$ and AGL radiators have been generated in two seperate runs of the simulation program. Two superimposed radiator layers were assumed. This is a sensible procedure since it has been shown in prototype study that this type of configuration provides good results [8].

The momentum resolution of the spectrometer used for mass reconstruction, was estimated from the current status of the magnet and tracker architecture [4], using the relations given in ref [9]. The expected mean value is minimum in the central RICH sensitivity region around $3-10 \mathrm{GeV} / \mathrm{c}$, of the order of $\frac{\Delta p}{p} \approx 1 \%$, increasing on both sides $[10]$.

The particle absorption in the matter of the spectrometer upstream of the RICH has not been taken into account. The thickness of matter will be about $5 \mathrm{~g} / \mathrm{cm}^{2}$ of material [4], i.e., $\approx 20 \%$ interaction length assuming $\Lambda_{I} \approx 25 \mathrm{~g} / \mathrm{cm}^{2}$, which would damp the incoming Be flux by about the same fraction.

\section{Results}

The program was run for six weeks equivalent counting time of the experiment, which is expected to be running for several years. This is about 20 times less than the currently nominal full statistics expected. The results obtained are already highly significant however, and illustrate very well how the new data will compare with the existing ones, and how much AMS will improve on the current situation.

\section{1. ${ }^{10} \mathrm{Be} /{ }^{9} \mathrm{Be}$ momentum distribution}

The momentum range has been divided into $0.5 \mathrm{GeV}$ and $1 \mathrm{GeV}$ bins for $\mathrm{NaF}$ and aerogel radiator respectively. For each momentum bin, the mass spectrum has been fitted with gaussian shapes centered at the known value for the mass of the isotope. The results are shown on figure 1. It is seen that a good separation for $\mathrm{Be}$ ions is obtained over the range established in previous simulation studies [5], up to $\approx 5 \mathrm{GeV} / \mathrm{c}$ for $\mathrm{NaF}$ and $\approx 13 \mathrm{GeV} / \mathrm{c}$ for aerogel.

The final momentum distribution of the ${ }^{10} \mathrm{Be} /{ }^{9} \mathrm{Be}$ abundance ratio obtained from the sample of reconstructed ${ }^{10} \mathrm{Be}$ ions is shown on figure 2 . It can be seen on this figure that the two radiators considered, $\mathrm{NaF}$ and Aerogel $\mathrm{n}=1.025$, have very complementary momentum ranges and offer a wide overall momentum dynamics altogether, extending 



Figure 1. Mass distribution spectra for each momentum bin and corresponding fits for the three ions, obtained with $\mathrm{NaF}$ radiator (left) and Aerogel $(\mathrm{n}=1.025)$ radiator (right).

from below $1 \mathrm{GeV} / \mathrm{c}$ per nucleon at the lower end of the range for the $\mathrm{NaF}$ radiator, up to about $13 \mathrm{GeV} / \mathrm{c}$ per nucleon at the upper end of the range for the aerogel radiator. This is about the best possible range reachable with solid state radiators in the particular AMS conditions. It is also seen that this range nicely overlaps with the region of best sensitivity to the transport variables of Cosmic Rays. Using one single of the two radiators would severely truncate the momentum range one or the other side. Going for a compromise on the value of the refractive index like (aerogel) $n=1.14$ would truncate the momentum range from both sides, since no single radiator could achieve the coverage in momentum dynamics obtained here [5].

\section{Conclusion}

The simulation of the cosmic Be isotopes detected by the RICH of AMS has shown that the distribution of the ${ }^{10} \mathrm{Be} /{ }^{9} \mathrm{Be}$ ratio should be measured with unprecedented statistical accuracy and with a good precision over a momentum range for particle identification matching the domain of largest sensitivity of the ${ }^{10} \mathrm{Be} /{ }^{9} \mathrm{Be}$ ratio to the galactic propagation parameters. This momentum range can be covered only with a combination of two Cerenkov radiators such as sodium fluoride at low momenta, and silica aerogel $(\mathrm{n} \approx 1.025)$ at high momenta. A similar evaluation is being conducted for the ${ }^{26} \mathrm{Al}$ isotope. 


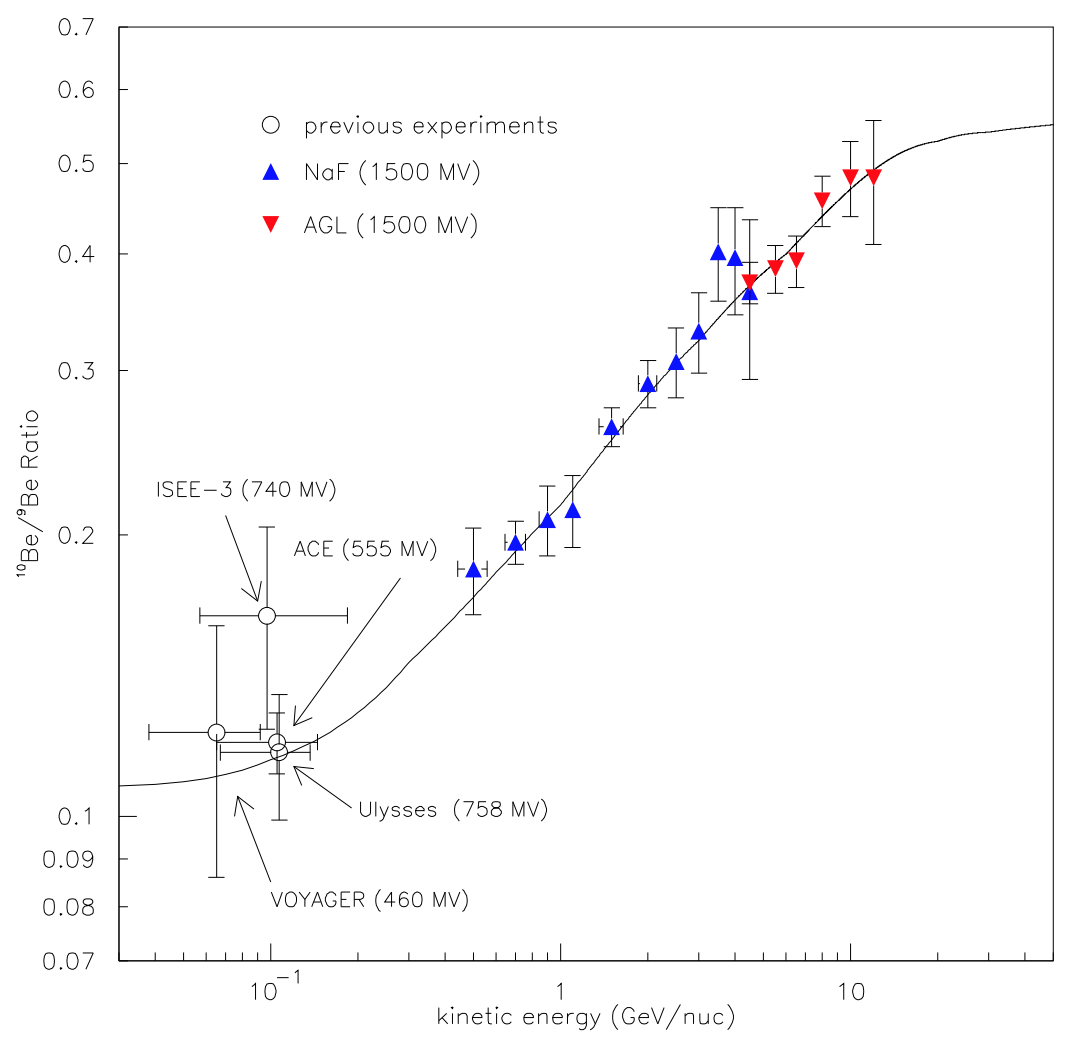

Figure 2. Expected ${ }^{10} \mathrm{Be} /{ }^{9} \mathrm{Be}$ ratio to be measured with AMS on the ISS over six weeks of counting time for each radiator of the $\mathrm{RICH}$ counter, $\mathrm{NaF}$ and aerofel. The value of the solar modulation parameter is given by the numbers in parenthesis for each experiment or simulation. The experimentaldata are from references [1].

\section{REFERENCES}

1. A. Lukasiak et al., ApJ 423(1994)426; J.J. Connell, ApJ 501(1998)L59; N.E. Yanazak et al, Proc. of the ICRC conf., Salt Lake City, 17-15 august 1999;

2. V.S. Berezinskii et al., Astrophysics of cosmic rays, NHPC, 1990.

3. A.W. Strong and I.V. Moskalenko, Ap. J. 509(1998)212

4. For details, see http://ams.cern.ch/AMS/ams_homepage.html

5. M. Buénerd and Z. Ren, NIM A 40531, November 2000, in press.

6. J.A. Simpson, Ann. Rev. Nucl. and Part. Sci. 33(1983)323; B. Wiebel-Sooth, P.L. Biermann, and H. Meyer, A\&A, 330(1997)389

7. R.A. Mewaldt, Cosmic abundances of matter, AIP Conf. proc. 183, 1989, p 124.

8. T. Thuillier et al., In preparation for NIM A.

9. Review of Particle properties, Euro. Phys. J. C3(1998)1

10. A. Bouchet et al., AMS internal report 2000_05_05, March 2000. 